To cite this Article: L. Ranta, A. Sievers, A. Guilland (2017) SHARED RESPONSIBILITY OF HIGHER EDUCATION INSTITUTES (HEI) AND THEIR PARTNERS IN ASSURING NURSING STUDENTS' EMPLOYABILITY SKILLS, ICERI2017 Proceedings, pp. 1247-1255.

doi: $10.21125 /$ iceri.2017.0412

URL: https://library.iated.org/view/RANTA2017SHA 


\title{
SHARED RESPONSIBILITY OF HIGHER EDUCATION INSTITUTES (HEI) AND THEIR PARTNERS IN ASSURING NURSING STUDENTS' EMPLOYABILITY SKILLS
}

\author{
L. Ranta, A. Sievers, A. Guilland \\ Laurea University of Applied Sciences (FINLAND)
}

\begin{abstract}
Considerable technological changes have modified our world during the last centuries. Jobs and their content evolve with such a space that anticipation of future skills requirements is extremely challenging. Huge expectation are set on education in bringing the appropriate solutions. Especially higher education (HE) should assure that graduates are agile, have a solid understanding of how the workplaces work. Graduates should be prepared see how their skills fit into to the changing environments of working life and for moving across jobs and sectors. The challenges of higher education are not limited to the changing requirements of working life.
\end{abstract}

Also the learners and their expectations and practices have changed. Most adult learners benefit from internet to find and make use of information on their own. People tend to avoid long, drawn out courses that take time to work through, and prefer to use short pieces of content - both instructional and informational - and share ideas and information with others. Learning happens much outside the class room by being immersed in work or in social networks, gradually assimilating new ideas and experiences, in many instances unintentionally and without even realising it. Formal learning should adapt to the wave and adjust the offering to the real-life context of the learners. Digitalisation including eLearning needs to be developed as an essential part of higher education.

The goal of this study was to increase knowledge on the competences needed in different working environments of nurses and to improve nursing students' employability skills. Nineteen private, public and third sector nurses' employers were interviewed in Southern Finland. The EntreComp Framework was used in the interviews which were audio-video recorded.

The most essential competences of nurses turned out to be: 1) mobilizing recourses (e.g. evidencebased nursing and clinical nursing skills), 2) mobilizing others (e.g. interaction skills), 3) taking the initiative (e.g. initiative, independency, and professionality), 4) coping with uncertainty, ambiguity and risk (e.g. decision making, acting under pressure and stress) and 5) working with others (e.g. teamworking, co-operation).

In the future the special attention needs e.g. language skills, technological skills, knowledge searching skills, multicultural skills, ability to comply with changes, interaction and guiding skills and knowledge to care for different patient groups.

To succeed in answering to the changing requirements of working-life, business and universities should share the responsibility and create awareness on both sides of the complexities of the other. This collaboration should also enable development of internships which really enable students to develop their skills in various aspects and learn to take over responsibilities.

Students should recognise their own role and responsibility and take an active role in learning and develop their ability to assess their performance and match it to those of the field where they wish to work.

Higher education should act as a facilitator of learning in the collaboration where all partners, education, business and learners, assure their active role and responsibilities. This is this only way how the challenges of future working-life skills can be assured efficiently.

Keywords: Employability, employee, entrepreneurial, skills, higher education, business, students, graduates, collaboration, responsibility. 


\section{INTRODUCTION}

Considerable technological changes have modified our world during the last centuries. This ongoing development revolutionizes all facets of our lives; working life as well as our societies and lifestyles. Many jobs disappear and others, many of which have not yet been even created, will be replacing them. A great part of the young school aged children today, will end up in jobs that do not exist today [1].

At the same time, unemployment has become a serious problem in both industrialized and undeveloped countries. Especially youth unemployment bears also a strong risk of various societal problems. According to the World Bank, 620 million young people are currently not in employment, education or training (NEETT). Globally, 73 million youth are registered unemployed. Moreover, only 200 million jobs are awaiting the 600 million young slated to enter the job market in the next decade [2].

In Europe, graduates are known to submit some 60 applications for their first job and with time some give up hope of getting employed in their field. In average, one out of two European graduates are worried about their career [3].

While there are more and more people in Europe looking for work, there are simultaneously employers who cannot find the skills they need. Over a fourth $(27 \%)$ of employers have left a vacancy open in the past year because they couldn't find anyone with the right skills. Three out of four (74\%) European education providers consider that preparing graduates for work, while only one graduate $(38 \%)$ or employer (35\%) out of three thinks so [3].

The skills mismatch affects young people everywhere. The exact cause of the skills mismatch is difficult to pin down, it can be seen as a combination of school curriculums neglecting vocational, entrepreneurial and employability training in favour of more traditional academics, poor connections between the private sector and schools to promote training and work experience and a lack of instruction in how to harness life-skills most students already have [2].

\subsection{Future skills requirements}

Jobs and their content evolve with such a space that anticipation of future skill and competence requirements remains extremely challenging even though much effort is put to predicting them. In recent year, meta-cognitive, soft, transversal or entrepreneurial skills, have been in the centre of discussion among researchers, education institutes, authorities and decision makers. In 2006 the European Commission (ANC 2006/962/EC) defined the eight Key Competences, necessary for all members of a knowledge-based society [4].

Transferable competences are defined as competences that can be transferred from one job to another [5]. They are sometimes also called transversal, generic, soft or employment competences. They can be learned within an educational or a social context and then transferred to a career, and generally be used and developed in all areas of people's life. Transversal competences include digital skills, learning skills, social and civic skills, sense of initiative and entrepreneurship, and cultural awareness and expression.

Ten years later, entrepreneurship was defined as the competence, which applies to all spheres of life: from nurturing personal development, to actively participating in society, to (re)entering the job market as an employee or as a self-employed person, and also to starting up ventures (cultural, social or commercial). Entrepreneurship is defined as "acting upon opportunities and ideas and transforming them into value for others or horizontal and entrepreneurial management of the various domains in all areas of life". The EntreComp conceptual considers that entrepreneurship consists of 15 different competences or building blocks as presented in figure 1. In various contexts the more emphasis may be put on some of the competences and less on others [6]. 


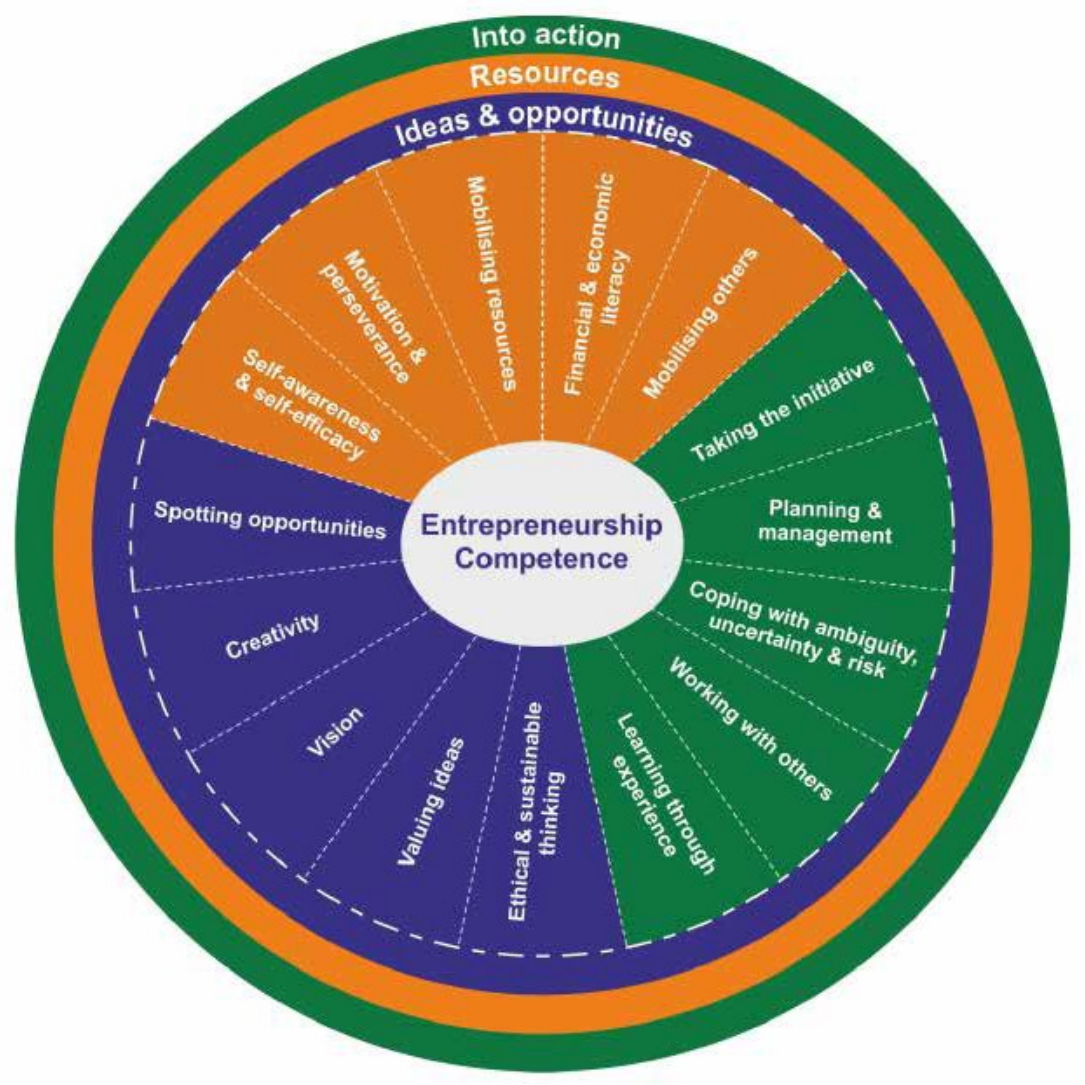

Figure 1: Entrepreneurship competences - EntreComp Framework [6].

As shown in figure 1, the entrepreneurship consists of 15 competences which can further be divided in three groups: 1) Into action (taking the initiative, planning \& management, coping with ambiguity, uncertainty \& risk, working with others, learning from experience); 2) Resources (self-awareness \& self-efficacy, motivation \& perseverance, mobilising resources, financial \& economic literacy, mobilising others); 3 ) Ideas and opportunities (spotting opportunities, creativity, vision, valuing ideas, ethical \& sustainable thinking). These fifteen competences can be assessed with the help of various assessment methods such as with the assessment framework developed in the Erasmus+ Socces project [7].

The assessment of transferable competences, such as entrepreneurship, is complex and particularly challenging since these competences are not easily definable, neither completely separated from competences related to contents. The methods for assessment of transversal competences should therefore e.g., use models of competence development based on cognitive research, but transforming psychometrics to deal with new kinds of assessment and making students' thinking visible; account for new modes of communications (e.g., ICT); include collaboration and teamwork (i.e., integrate individual performance evaluation by assessing collaborative tasks) [8].

Less than half of employers are satisfied by their workforce's skill levels [3]. The constant evolution of technology and sciences create a need for self-assessment of one's competences and skills as well as updating and expanding knowledge and skills.

\subsection{Development of the required skills and competences}

Competences are not innate, inborn characteristics but learnt characteristics. They can be learned within an educational or a social context and then transferred to a career, and generally, be used and developed in all areas of people's life. Learning competences is an ongoing, lifelong, learning process which occurs in multiple settings. "The settings and social institutions relevant to the development of competencies besides school are relatives, peers, work, political life, religious life, cultural life, etc. Competency learning is not only a matter of personal effort. The development of competences assumes a favourable social and ecological environment, which includes but goes beyond the satisfaction of basic needs (food, housing, health, etc.). It is also dependent on the quantity and quality 
of learning opportunities. Therefore, the structure of the economy and social institutions plays a major role in the development of competencies." [9].

Recent studies have shown that people with so called "growth mind-set", who believe that they can develop their competences, (vs fixed mind-set) work and learn more effectively and display a desire for challenge and resilience in the face of failure. Whereas, people with a 'fixed mind-set' believe that you are either smart or you are not" and therefore they are not interested in developing themselves and are unwilling to tackle new challenges. Studies show that when students undertake an intervention to move them from a "fixed" to a "growth mind-set" they immediately start performing at higher levels [10].

\subsection{Role of Higher education and their partners}

\subsubsection{Higher education (HE)}

Huge expectation are set on education in bringing the appropriate solutions. Especially higher education (HE) should assure that graduates are agile, have a solid understanding of how the workplaces work. Graduates should be prepared see how their skills fit into to the changing environments of working life and for moving across jobs and sectors.

The challenges of higher education are not limited to the changing requirements of working life. Future challenges require the rethinking of teaching and learning approaches. The learners and their expectations and practices have changed. Most adult learners benefit from internet to find and make use of information on their own. People tend to avoid long, drawn out courses that take time to work through, and prefer to use short pieces of content - both instructional and informational - and share ideas and information with others. Learning happens much outside the class room by being immersed in work or in social networks, gradually assimilating new ideas and experiences, in many instances unintentionally and without even realising it. Formal learning should adapt to the wave and adjust the offering to the real-life context of the learners. Digitalisation including eLearning needs to be developed as an essential part of higher education.

Learning and teaching transversal or more specifically entrepreneurship competences challenges $\mathrm{HE}$ teaching and learning approaches. This can include: transition from teacher to learner centred approach; shift of responsibility for learning to the learner; offer team-working opportunities aside to individual work; replace pure memorizing by learning to find, critically evaluate, select and apply information; evolution from theory centred approach towards educational environments and methods where learning happens "in, through and for" authentic working-life challenges; transition from monodisciplinary to multidisciplinary, interdisciplinary or transdisciplinary learning environments; integration of digital communication for promotion of collaboration and participation and avoidance of exclusion $[7,11]$.

\subsubsection{Partners}

Employers' knowledge and experience can and should be used, in various ways during the learning process, to help graduates to acquire the knowledge, skills, competences and positive attitude towards work that will support their chances of finding a suitable job or starting own business. Worldwide organisations such as OECD but also European Council and local authorities in various countries have repeatedly stressed the need for stronger partnership between education and working world for enhancing learners' employability, entrepreneurial potential and familiarity with the working world.

The review compiled by Professor Sir Tim Wilson [12] presents numerous examples of how business and education can collaborate. Big companies have traditionally been prominent partners of education whereas more emphasis could be put on developing collaboration with small and medium size enterprises (SME). This can consist of development of internships, job placements, business mentors as well as integration of business in learning and teaching activities through authentic working life challenges such as is the case in various universities in Northern Europe including Laurea University of Applied Sciences which applies the Learning by Developing (LbD) pedagogical method since 2005 [13]. 


\section{METHODOLOGY}

In this study, nineteen private, public and third sector nurses' employers were interviewed in Southern Finland by semi-structured interviews to find out needs of competences in working as a nurse.

The working environment of the interviews in private sector were home care, sales consultant work in pharmaceutical industry, the rehabilitation unit of people with mental disorders and substance abuse, ambulance services, reception centre for asylum seekers and work in simulation learning environment in university of applied science.

The working environment of the interviews in public sector were nurse's appointment, case manager's work, discharge team and rehabilitation ward in health centre in primary health care, in coordinated accident and emergency services, the class with children mental disorders in comprehensive school and prison hospital. In specialized care, environments were operation theatre, intensive care unit and acute as well as ward and outpatient care psychiatric units

In third sector, the working environments of the interviews were family shelter and international humanitarian aid work.

The study aimed at answering three main research questions:

1 What are the employability competences of nurses in the given working environment?

2 Do young nurses express the required competences?

3 How will required competences change in the future?

The interview themes were:

1 The most essential working life competences of nurses to be recruited

2 The less essential working life competences of nurses to be recruited

3 The incidence of the required competences among job applicants and ways in which they are defined in the recruitment process

4 Working life competences in the future

The EntreComp Framework (Figure 1) was used in the interviews for identifying the competences as well as in the analysis of the results. The data collection process is described in a parallel article by the same authors.

\section{RESULTS}

This study resulted in 19 interviews of persons who were considered to be aware of the of the employability requirements of nurses in private, public and third sector in Finland. The interviewees all hold a managerial or team leader position and participate in the recruitment process. The interviews were made by nursing students (15 interviews) and a lecturer/researchers (four interviews). The collecting data was analysed by lecturers. The reason for not having all the interviews done by students was due to lack of permission from the employer who also refused to have the interviews video-recorded as the other interviews.

The essential competences of nurses at present and in the future as well as their prevalence among job applicants are presented in the following chapters.

\subsection{The most essential competences of nurses}

According the interviews, the five critical competences requested by employers of nurses in Southern Finland in spring 2017 were the following:

1 Working with others e.g. team-working, co-operation, multi-professional working and collegiality

2 Mobilizing resources e.g. evidence-based nursing, clinical nursing skills, IT-skills, good professional skills and guidance skills.

3 Coping with uncertainty, ambiguity \& risk e.g. risk management, ability to make decisions, acting under pressure \& stress, acting in changes and flexibility

4 Mobilizing others e.g. interaction skills, ability to learn and teach and generally social skills 
5 Taking the initiative e.g. sense of initiative, consistency \& independency, working professionally $\&$ multidisciplinary and expressing situational awareness

In the future more emphasis will be set on language and multicultural skills. According to the interviewees this is due to global changes, internationality and mobility of employees as well as the ongoing social and health service reform in Finland and the changes of the customers' role. The decreasing resources and the new tasks and responsibilities in nurses as well as the progress of medicine influence the nurses' work and the expectations set to the nursing staff. Therefore also technological skills, information searching, knowledge to care for different patient groups, ability to comply with changes, innovativity, renewability and responsibility will become more relevant.

\subsection{Essential competences among job applicants}

The interviewees evaluated the prevalence of the essential competences among job applicants using a common/quite common/rare/very rare scale and reported the easiness of identifying these competences in recruitment situations. According to the results job applicants often have many of the essential competences but the existence or level of the competences is difficult to define and identify. Only the one of the 19 interviewees had used an online assessment tool for assessing competences among job applicants before making the decision of recruitment. Most interviewees based recruitment decisions on documents such as references or recommendations, the job application document and the persons' achievements as indicated in the curriculum vitae. In most cases the essential competences were first identified in working life situations, after recruitment.

Three quarters $(16 / 19)$ of the interviewees answered that the capacity to "Work with others" was common or very common among job applicants. These competences were identified in different ways. Half of the interviewees considered it easy or quite easy to determine the existence of these competences among applicants, but one out of four (5/19) considered the identification difficult. None of the interviewees used any special assessment method for the competences.

According to the results, most job applicants are capable of Mobilising resources even though majority of the (15/19) interviewees considered it difficult to determine these competences in recruitment: less than half of the interviewees experienced it easy or quite easy to observe these competences in a job interview. It seems that the capability of Mobilizing others was easier to define. About half of the interviewees had experience in defining these competences among applicants and considered it easy or quite easy. Five interviewees thought the assessment was not easy and they and not used any tool for it.

The competences of Coping with uncertainty, ambiguity and risk were mainly considered common or quite common among job applicants. However, more than half of the interviewees found it difficult to define the presence of the competences among the applicants through the job interview. Only the four interviewees considered the evaluation easy.

Taking the initiative was considered a common or quite common competence among job applicants $(75 \%)$. Answers concerning the identification or evaluation of the competences differed radically: one out of two considered the evaluation easy and the other half difficult.

\section{CONCLUSIONS}

Youth unemployment is an alarming phenomena, which concerns all continents and societies. Several factors are considered responsible among them an evident skills mismatch of graduates and employer requirements.

Job seekers might partly be responsible through misunderstanding of the employee requirements and priorities set by the business. Young graduates may concentrate too much on, e.g., diplomas, theoretical knowledge and technical skills whereas recruiters look increasingly for transversal competences such as agility, flexibility, creativity, critical thinking, and problem-solving which traditional certificates do not give much information on.

To succeed in answering to the changing requirements of working-life, business and universities should share the responsibility and create awareness on both sides of the complexities of the other. Higher education should act as a facilitator of learning in the collaboration where all partners, education, business and learners, assure their active role and responsibilities. This partnership should be developed in a way that the various needs are developed and the ways of answering them is realised as a joint venture where all partners identify their role. 
Development of transversal competences during university studies requires modernisation of teaching and learning strategies such as:

- Transition from teacher to learner centred approach

- Shifting responsibility for learning from teacher to the learner

- Replacement of pure memorizing to finding, selecting, critically evaluating and applying information

- Creation of collaborative learning opportunities aside to individual work

- Evolution from theory centred approach to educational environments and methods where learning happens "in, through and for" authentic working-life challenges

- Transition from monodisciplinary to multidisciplinary, interdisciplinary or transdisciplinary learning environments

- Integration of digital communication for promotion of collaboration and participation and avoidance of exclusion

Business should identify their own needs and make them visible and understandable. In this transfer one practical way can be development of offering of internships and job placements where students can be designed real challenges and responsibilities which, if possible also vary during the length of the collaboration.

The promotion of digital learning together with development and use of more flexible digital learning and teaching methods enable flexible integration of different business partners in the learning process on local, national, international or even global level.

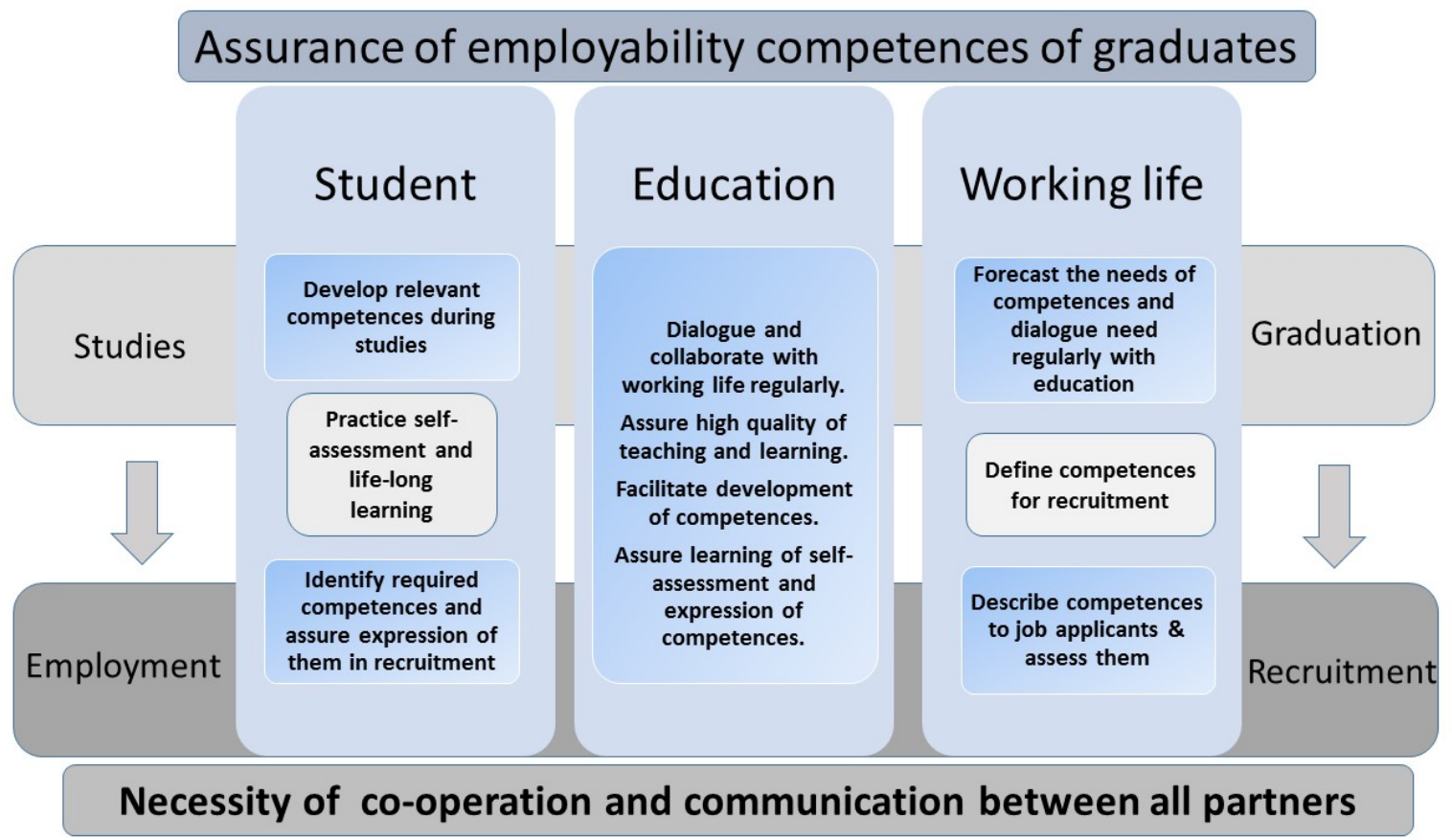

Figure 2. Development of employability through collaboration.

Through the transitions, also the students' role changes. They become responsible for learning, participate in determination of learning goals and hold an active role in the learning as well as in evaluating their learning outcomes. When holding an active role in the learning process, students can practice extrapolation and transfer of knowledge. In the modern "triple helix model" of education as presented in figure 2, business and learners, teachers have the role of facilitators of learning offering the means to building the content and choosing the methods. Content is used to build a knowledge base and to develop learning skills and learner's self-awareness.

However, the change does not appear through general recommendations. Especially SMEs often consider collaboration with education time consuming and are not willing to invest in it. Students 
experience difficulties in finding internships or job placements and the tasks offered during these periods often lack interest and variety. These could however offer business partners valuable occasions of challenging students and studying their suitability to different positions in the company and thus facilitate the recruitment process. As a result business could also communicate with the respective educational institutes on the needed skills and qualifications and thus participate in the iterative process of development of education.

\section{ACKNOWLEDGEMENTS}

This study was supported by the European Commission, Erasmus Plus program - Cooperation for innovation and the exchange of good practices, Strategic Partnerships for higher education, activity KA2, project no: 2016-1-IT02-KA203-024195. This paper reflects the views only of the authors and the Commission cannot be held responsible for any use which may be made of the information contained therein.

We thank our colleagues at Laurea University of Applied Sciences who provided insight and expertise that greatly assisted the study, although they may not agree with all of the interpretations/conclusions of this paper. We thank senior lecturer Tuija Marstio for the suggestions related to the study process as well as senior lecturer Anna Puisto and technical assistant Joel Korhonen for their help in the realization of the audio-visual material.

We would also like to show our gratitude to the private, public and third sector partners who enabled the data collection for the study.

\section{REFERENCES}

[1] World Economic Forum. The Future of Jobs Employment, Skills and Workforce Strategy for the Fourth Industrial Revolution. Geneva, World Economic Forum, 2016.

[2] Peace Child International. Youth Unemployment Causes and Solutions. With the post-2015 development agenda calling for decent work for all, understanding youth unemployment causes and solutions is key, 2016. Available at: https://peacechild.org/youth-unemployment-causesand-solutions/

[3] Mourshed M., Patel J., \& Suder K. Education to employment: Getting Europe's youth into work. McKinsey \& Co, 2014.

[4] Recommendation of the European Parliament and of The Council of 18 December 2006 on key competences for lifelong learning (2006/962/EC). Official Journal of the European Union L394/10, 30.12.2006.

[5] OECD. Skills for Innovation and Research, OECD Publishing, 2011. Available at: http://dx.doi. org/10.1787/9789264097490-en

[6] Bacigalupo, M., Kampylis, P., Punie, Y. \& Van den Brande, G. EntreComp: The Entrepreneurship Competence Framework. Luxembourg: Publication Office of the European Union, 2016.

[7] Guilland, A (Ed). 2017. Socces handbook- Assessment of Transversal Competences. Focus on Entrepreneurship, Sense of Initiative and Social Skills. Laurea Publications 77, ISSN-L 22425241, ISSN: 2242-5225 (online), ISBN: 978-951-799-454-5 (online).

[8] Terzieva L., Bolzani D. \& Luppi E. Assessment in Guilland, A (Ed). 2017. SOCCES handbookAssessment of Transversal Competences. Focus on Entrepreneurship, Sense of Initiative and Social Skills. Laurea Publications 77, 2017. ISSN: 2242-5225 (online).

[9] Rychen, D. S. \& Salganik, L. H. Definition and Selection of Key Competencies: Theoretical and Conceptual Foundations. INES GENERAL ASSEMBLY 2000. Available at: http://www.deseco.admin.ch/ bfs/deseco/en/index/02.parsys.69356. downloadList.26477.DownloadFile. tmp/2000.desecocontrib.inesg.a.pdf

[10] Boaler, J. Ability and Mathematics: the mind-set revolution that is reshaping education. FORUM 55(1): 143-150, 2013. Available at: www.wwwords.co.uk/FORUM. Retrieved from: http://www.you- cubed.org/wp content/uploads/14_Boaler_FORUM_55_1_web.pdf 
[11] Weimar, M. Learner-Centered Teaching: Five Key Changes to Practice. 2nd ed. San Francisco: Jossey-Bass, 2013. ISBN: 9781118119280.

[12] Wilson, T. A Review of Business-University Collaboration, February 2012. Available at: http://scholar.google.fr/scholar_url?url=http://dera.ioe.ac.uk/13842/1/wilson.pdf\&hl=fr\&sa=X\&sci sig=AAGBfm3xW1ImKGv4Nk6ja1KDHYlxqkUocA\&nossl=1\&oi=scholarr\&ved=0ahUKEwjbtuSej sPWAhWGaFAKHZh9CDAQgAMIJigAMAA

[13] Raij, K. Learning by Developing. Laurea Publications A-58. Helsinki: Edita Prima Oy, 2007. ISSN 1458-7211. ISBN 951-799-111-8. 